\title{
p57: A multifunctional protein in cancer (Review)
}

\author{
HUI GUO $^{1,2}$, TAO TIAN ${ }^{1}$, KEJUN NAN $^{1}$ and WENJUAN WANG ${ }^{1}$ \\ ${ }^{1}$ Department of Oncology, The First Affiliated Hospital, College of Medicine of Xi'an Jiaotong University, \\ Xi'an, Shaanxi Province 710061; ${ }^{2}$ Medical Oncology of Shaanxi Provincial People's Hospital, \\ Xi'an, Shaanxi Province 710068, P.R. China
}

Received January 14, 2010; Accepted March 4, 2010

DOI: 10.3892/ijo_00000617

\begin{abstract}
CDK) inhibitor, the first cell cycle regulator that is regulated by imprinting. p57 was initially considered to be a tumor suppressor based on its ability to regulate cell cycle progression through its $\mathrm{N}$-terminal domain. Now, it has been found that p57 is also involved in the regulation of other cellular processes including transcription, apoptosis, differentiation, development, and migration via its PAPA repeat and carboxyl-terminal domain. The multifunction of p57 participate in many processes in tumorigenesis involving in different mechanisms including loss of imprinting, loss of heterozygosity, promoter methylation, histone deacetylation and regulation of microRNAs. Moreover, upstream signaling pathways, protein-protein interactions and altered subcellular localization have also been reported to participate in abnormal expression of p57 resulting in the occurrence and progression of cancer. However, it is unclear whether p57 may play a dual role during tumorigenesis under different cellular processes similarly to its siblings. The presence of a nuclear localization signal in p57 is intriguing because it may affect the subcellular localization of p57, which can result in abnormal proliferation and motility of cells, and may be oncogenic under certain circumstances, as observed for $\mathrm{p} 21$ and $\mathrm{p} 27$.
\end{abstract}

\section{Contents}

1. Introduction

2. The structure of $\mathrm{p} 57$

3. The altered functions of $\mathrm{p} 57$ and cancer

4. Carcinogenic mechanism of $\mathrm{p} 57$

5. Perspectives: promoter or inhibitor of cancer?

Correspondence to: Professor Kejun Nan, Department of Oncology, The First Affiliated Hospital, College of Medicine of Xi'an Jiaotong University, No. 277 Yanta West Road, Xi'an, Shaanxi Province 710061, P.R. China

E-mail: nankj@163.com

Key words: p57, structure, abnormal functions, mechanism, cancer

\section{Introduction}

Any aberrations in normal cell cycle progression can lead to uncontrolled proliferation that can result in the occurrence and development of cancer. Cell cycle is a synchronized process that responds to both positive and negative regulators. The common negative regulators of the cell cycle are a class of proteins named the CDK inhibitors (CKI). The CKI can be grouped into two families: The INK4 family includes p $16^{\mathrm{INK} 4 \mathrm{a}}$, $\mathrm{p} 15^{\mathrm{INK} 4 \mathrm{~b}}, \mathrm{p} 18^{\mathrm{INK} 4 \mathrm{c}}$, and $\mathrm{p} 19^{\mathrm{INK} 4 \mathrm{~d}}$. The Cip/Kip family includes $\mathrm{p} 57^{\text {Kip2 }}, \mathrm{p} 21^{\text {Cip1 }}$, and p27 ${ }^{\text {Kip1 }}$ (1).

The $p 57$ is located in $11 \mathrm{p} 15.5$ and encodes a maternal expression. The expression of p57 not only differs spatially and temporally, but also has an organ and tissue-specific expression pattern. The level of p57 fluctuates during embryogenesis, throughout adulthood and in different phases of cell cycle. It is expressed in all major organs during embryogenesis and at high levels in important stages of differentiation in fetal organs. However, the expression of p57 declines or is undetectable in some adult organs including liver and spleen after birth. In adult tissues, p57 is mainly expressed in skeletal muscle, heart, brain, lung, kidney, pancrea, testis and placenta (2-5). In cell cycle, p57 is undulantly expressed in G1-S and G2-M transitions regulating cell proliferation and differentiation. Thus, it is commonly accepted that $p 57$ is a tumor suppressor gene. Recent research suggests, however, that p57 is actually a multifaceted protein that can regulate many cellular processes to be abnormal in tumorigenesis (6). There is conflicting evidence on the function of p57 in tumors. Consequently, there is a growing debate regarding whether p57 has an oncogenic effect under certain circumstances like p21 and p27 (6). This review focuses on the structure, abnormal functions and carcinogenic mechanism of p57 to investigate its role in tumorigenesis.

\section{The structure of p57}

The human p57 (hp57) is comprised of 316 amino acids and three domains shown in Fig. 1, contrasted with human p21 (hp21) and human p27 (hp27) (2,3). In the past, we focused on the cyclin-CDK regulatory domain. However, a fraction of BWS patients exhibit major point mutations that are located outside of the cyclin-CDK regulatory region (7). This phenomenon supports that p57 can participate in the regulation of other functions via its PAPA repeat and QT domains in tumorigenesis. 


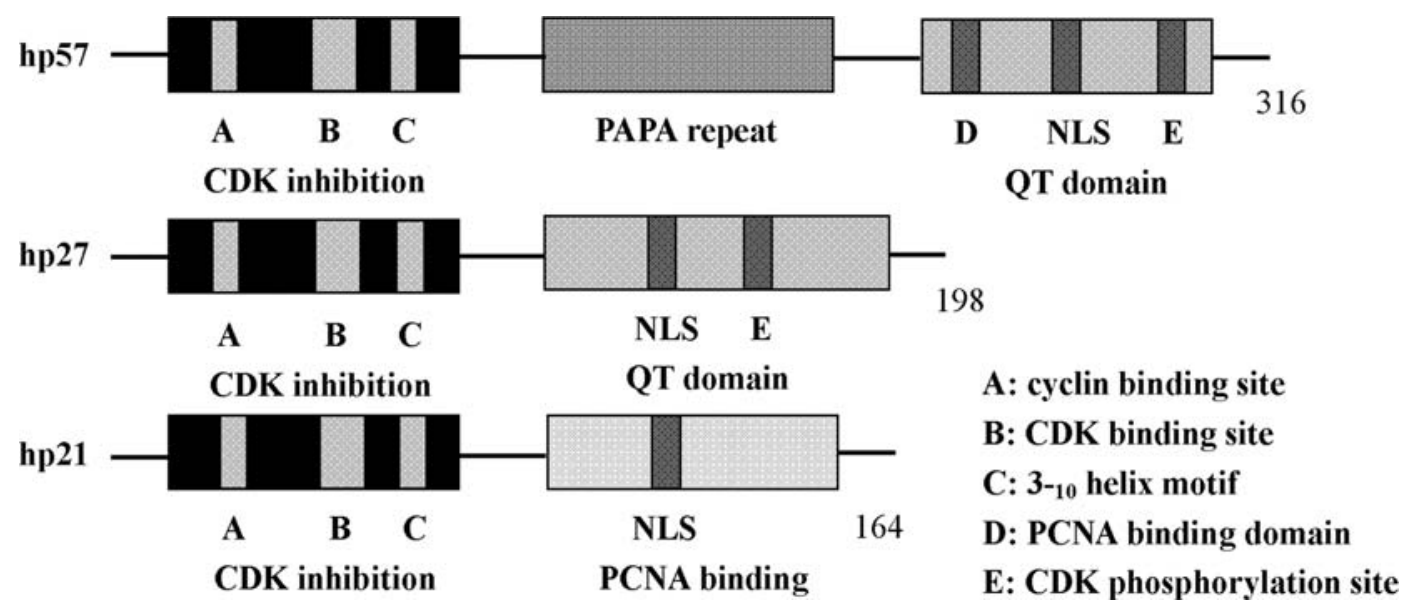

Figure 1. The structure and functional domains of hp57, conparison with hp27 and hp21. hp57 consists of three domains: a highly conserved N-terminal, a carboxyl-terminal and an internal PAPA repeat domain. The $\mathrm{N}$-terminal domain is a conserved CDK inhibitor domain that is also present in the hp21 and hp27. This region contains three domains: the cyclin binding site (A), CDK binding site (B) and the 3-10 helix motif (C). The carboxyl-terminus of hp57 has a QT domain that contains three motifs: a nuclear localization signal (NLS) is similar with hp21 and hp27; the PCNA binding domain is similar in hp21, but not found in hp27 (D); a CDK consensus phosphorylation site is conserved between hp57 and hp27, but not found in hp21 (E).

The N-terminal domain. The N-terminus of p57 has been shown to be necessary and sufficient for inhibition of proliferation in tumor and is highly conserved among Cip/Kip family. This region contains three conserved domains: the cyclin and CDK binding sites and the $3-_{10}$ helix motif. The $3{ }^{-}{ }_{10}$ helix is implicated in inhibiting CDK2 kinase activity specifically and is indispensable to inhibit cyclin $\mathrm{A} / \mathrm{CDK} 2$ and cyclin E/CDK2 (8). The cyclin and CDK binding sites of p57 can bind and inhibit the activity of cyclin E/CDK2, cyclin A/CDK2, cyclin E/CDK3, and cyclin D2/CDK4 kinase complexes in a cyclin-dependent manner. It shows considerably less activity toward cyclin B/CDK1 and cyclin D2/CDK6 complexes. Furthermore, p57 can affect different cyclins directly but very weakly (2). On the one hand, the Nterminal cyclin-CDK binding domain of p57 occludes a substrate interaction domain on a cyclin subunit, leading to its insertion into the catalytic cleft of a CDK to prevent ATP binding and catalytic activity. On the other hand, the binding specificity of p57 is modulated by its phosphorylation of distinct residues and protein-protein interactions $(6,9)$. In addition, the cyclin and CDK binding sites of p57 are implicated for its degradation by ubiquitination to regulate p57 levels and suppressive functions (10).

The PAPA repeat. The internal domain of p57 consists primarily of an alternating proline-alanine repeat (PAPA repeat), which contains a consensus mitogen-associated protein (MAP) kinase phosphorylation site (2). No equivalent PAPA domain is present in either p21 or p27. The PAPA repeat may confer the ability to establish specific proteinprotein interactions affecting the localization of p57 or its ability to function as a CKI in vivo (9). The presence of the PAPA repeat provides a high frequency mechanism for expansion mutation (2). The deletions in the PAPA repeat are associated with increased risk for a variety of cancers. It was found that 16 out of 105 patients with cancer of the breast, bladder, or liver, had deletions within the PAPA repeat of p57 (11). Moreover, the central region of p57 is known to be essential for the interaction with LIM-kinase 1
(LIMK-1), which enables it to participate in the motility of tumor cells (12).

The carboxyl-terminal domain. The carboxyl-terminus of p57 consists of a QT domain which exhibits sequence similarity to the QT domain of p27. The QT domain has three motifs: a nuclear localization signal (NLS), PCNA (proliferating cell nuclear antigen) binding domain and a CDK consensus phosphorylation site. The QT domain involves many functions including proliferation, apoptosis and cytoplasmic localization in tumor development. The location and adjacent sequence of the CDK consensus phosphorylation site is highly conserved between $\mathrm{p} 57$ and p27, but not found in p21. This site may be involved in feedback regulation of p57 by their target CDKs to regulate proliferation (3). The PCNA binding domain of p57 can bind with PCNA to prevent DNA replication in vitro and entry into S-phase in vivo, this affinity is weaker than that of p21 (13). The QT domain of p57 also involves in apoptosis though the c-Jun NH2-terminal kinase/stressactivated protein kinase (JNK/SAPK) pathway in tumor cells (14). The mutations in the QT domain do not make the protein nonfunctional, rather it is made ineffective because it cannot reach its target cyclin/CDK complexes. Some researchers think it is a result of truncations in the NLS, which prevents entry of p57 into the nucleus.

In the past, p57 was considered to express in the nucleus, however, cytoplasmic expression of this protein has been demonstrated in various tissue, tumors and derived cell lines (15-20). A p57 expression construct missing the carboxylterminus (amino acid 281) leads to the cytoplasmic localization of p57 and its exclusion from the nucleus (2). In some Beckwith-Wiedemann syndrome (BWS) patients, p57 accumulates in the cytoplasm because the NLS of p57 is absent (21). These findings suggest that nuclear localization may be specified by the NLS. The cytoplasmic expression of p57 has been reported in esophageal carcinomas, non-small cell lung cancer (NSCLC) and hepatocellular carcinoma (HCC), but has not been further investigated $(15,17,22)$. Cytoplasmic p57 can interact with and regulate the activity of 
LIMK-1, which implies the motility of tumor cells $(12,18)$. Recently, numerous studies show that the p21 and p27, p57 siblings, in the cytoplasm of cancer cells are involved in tumor invasion and metastasis (23). The NLS of p27 (RKRPAT sequence) is similar to the NLS of p57 (KRKR sequence). The inactivated NLS of p27 leads to its cytoplasmic localization by Akt phosphorylation conferring p27 an oncogenic function and making such localization a negative prognostic marker (24). The QT domain of p57 has some phosphorylation sites. However, it has not been proven that phosphorylation can affect the QT domain of p57 to change subcellular localization. Although more studies are need to make clear the relationship between the subcellular localization and biological function of $\mathrm{p} 57$, some researches support that p57 may play different even opposite roles in the nucleus and the cytoplasm.

\section{The altered functions of p57 and cancer}

In cancer biology, the abnormal functions of p57 participate in cancer initiation and progression. p57 was initially reported to inhibit proliferation. Thus, it is believed to be a tumor suppressor gene. Now it was found that p57 is also involved in the regulation of other cellular processes including apoptosis, differentiation, development, and migration in tumorigenesis (6). Clinical studies also show p57 is a marker of aggressive phenotype and prognosis of tumors.

Abnormal cell cycle regulation. p57 plays a very important role in proliferation of tumor cells. Specifically, p57 can regulate cyclins, CDKs and cyclin-CDK complexes in the G1-S and G2-M transitions, modulating both DNA reduplication and cell mitosis. Thus, absence of p57 results in an unusual increase in the number of cells in S- and M-phase in tumors. Loss of p57 in tumor cells leads to: i) The assembly of cyclin D/CDK6 prevents formation of the growth-suppressing form of $\mathrm{Rb}$, which sequesters E2F members and activates transcription of E2F-responsive genes. ii) The continued activity of cyclin E/CDK2 promotes completion of G1 phase and entry into $\mathrm{S}$ phase. iii) The continued activity of cyclin $\mathrm{A} / \mathrm{CDK} 2$ and increasing the levels of cyclin A promote entry into and passage through $\mathrm{S}$ phase (25). In addition, p57 takes part in endocycles, acytokinetic mitosis and cell fusion to produce multinucleated giant cells during terminal differentiation of some mammalian tissues by inhibition of CDKs $(26,27)$. In rat choriocarcinoma, the presence of abnormal multinucleated giant cells corresponds with the level of p57 expression (28). p57 can also modulate cell cycle progression dependent on the PCNA binding domain of p57 in tumor. Disruption of either CDK/cyclin or PCNA binding can partially reduce the ability of p57 to inhibit cell proliferation. However, loss of both inhibitory functions completely eliminates the suppressive activity of p57 (13). Accordingly, it has been reported that the decreased expression of $\mathrm{p} 57$ coincides with overexpression of PCNA, suggesting a contribution to the occurrence and progression of lung, pancreatic and hepatocellular carcinoma $(17,29,30)$. p57 can provide an additional barrier against indefinite proliferation influenced by telomere length indirectly. In human mammary epithelial cells (HMECs), expression of p57 inhibits the conversion of conditionally immortal cells to the fully immortal state, which is a rate-limiting step in cancer progression (31).

p57 and apoptosis in cancer. p57 can either promote or inhibit apoptosis depending on the cellular context and regulative pathways in tumor cells. Some phenotypes of the $p 57^{-/}$mice display an increase in apoptosis because of a failure to exit the cell cycle and initiate differentiation (32). p57 can suppress pro-apoptotic factors at checkpoints to avoid unintended cell apoptosis under special circumstances, such as during endocycle and tumorigenesis (26). The most common way in which p57 modulates apoptosis is by acting on cyclin-CDK complexes to arrest the cell cycle. Loss of p57 expression promotes E2F1-dependent apoptosis in $p 57^{-/-}$mice (33). In breast cancer cell lines, small molecule CDK inhibitor BMS387032 transcriptionally activates p57 in an E2F1-dependent manner, which serves to limit the E2F1 apoptotic activity (34). The impact of p57 on apoptosis can be regulated by other signaling pathways and transcription factors. The QT domain of p57 can bind to the stress-activated signaling proteins as an endogenous inhibitor of the JNK/SAPK pathway to block apoptosis (14). In p57-null oral carcinoma cells, exogenous expression of p57 suppresses EGCG (epigallocatechin-3gallate)-induced apoptosis via inhibition of JNK signaling (35). Kruppel-like factor 4 (KLF4) upregulates p57 expression, which in turn inhibits the JNK/SAPK pathway in cancer cells (36). Apart from this, p57 promotes staurosporine-induced apoptosis by translocating to the mitochondria and promoting Bax, caspase-9, and -3 activities in cancer cells (37). There are numerous clinical studies to demonstrate that the abnormal expression of p57 accompanies imbalance of proliferation and apoptosis in cancer cell lines and human tumor tissues $(34,38,39)$. In cancer therapy, the absence of p57 has an influence on proapoptotic functions of anti-cancer drugs, which results in drug resistance and a poor prognosis. The selective p57 expression sensitizes cancer cells to apoptotic agents such as cisplatin, etoposide and staurosporine (37). The silencing of p57 suppresses the p73-mediated apoptosis in lung and colorectal cancer cell line caused by cisplatin treatment (40). As a downstream regulator, apoptotic effects of p57 depend on the different signals of upstream pathways and regulators, which allows for the selective removal of damaged cells.

Role of p57 in invasiveness and metastasis of cancer. Tumor invasiveness and metastasis depend on altered regulation of cell migration, which requires the regulators of cytoskeletal dynamics, in particular the Rho family (41). Researchers have identified a negative feedback loop between the Rho pathway and CKIs; the Rho pathway controls the expression and activities of CKIs, while CKIs negatively regulate various proteins in the Rho pathway. This reciprocal interaction results in the coordinated control of cellular proliferation and cell migration in tumors (23). It has been indicated that p57 participates in coordinating the timing of three events: neuronal differentiation, cell cycle exit, and neuronal migration during nerve system development (42). p57 is extensively expressed in skeletal muscle cells during all stages of embryonic development, which suggests p57 is 


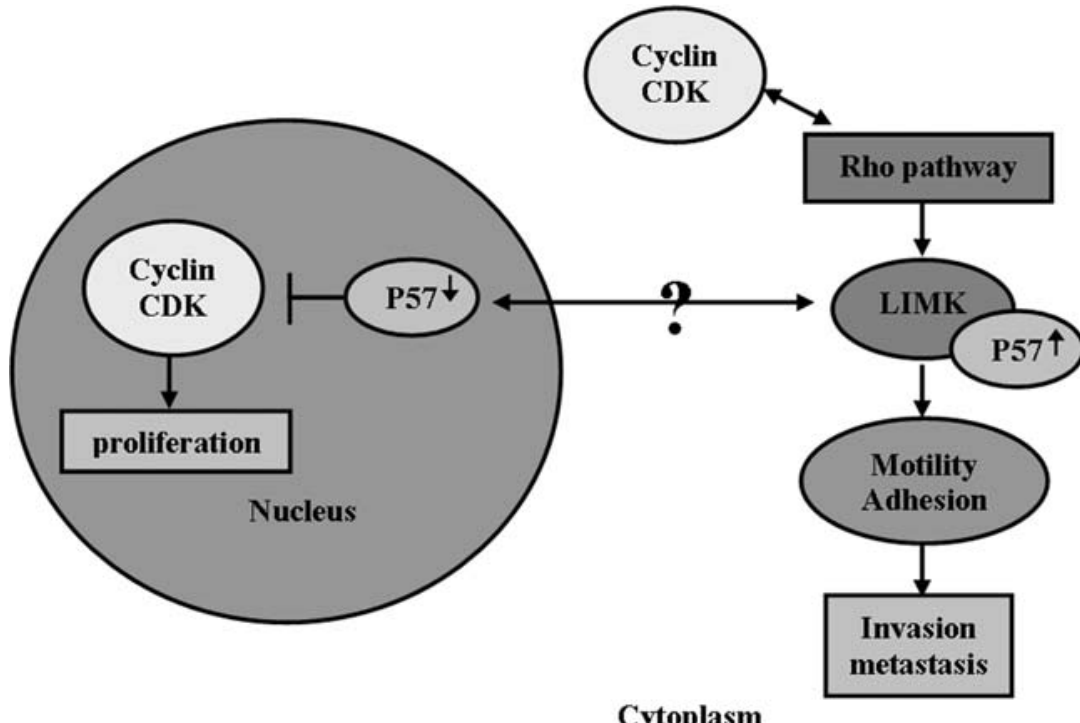

Figure 2. Regualtion of invasiveness and metastasis by p57 in cancer cells. p57 can inhibit the Rho/ROCK/LIMK/Coffilin signaling pathway. p57 interacts and enhances activity of LIMK-1 and results in actin stress-fiber formation in cancer cells, which ultimately affects cancer cell motility. In the cytoplasm p57 controls LIMK-1, which leads to an increase of p57 in the cytoplasmic fraction and a decrease in the nuclear fraction. Thus, subcellular localization of p57 is critical in the regulation of cancer cell proliferation and migration. It is unclear how p57 moves between the nucleus and cytoplasm.

involved in cell migration during development (43). In Schwann cells, reduced level of p57 participates in cytoskeletal rearrangements and leads to actin filament stabilization, altered cell morphology, and down-regulation of promyelinating markers (44). Thus, the inability to appropriately halt growth of p57 can lead to malformation during development, and to carcinogenesis and metastasis.

The Cip/Kip proteins can inhibit the Rho/ROCK/LIMK/ coffilin signaling pathway at distinct levels involving angiogenesis, invasion and metastasis of cancers (45). Vlachos and Joseph found that p57 could interact and enhance activity of LIMK-1 and resulted in an increase in the phosphorylation and consequent inactivation of cofilin. Accordingly, selective p57 expression promoted actin stress fiber formation in cancer cells. They further demonstrated p57 expression could reduce the actin mobile fraction, which affected its turnover rate in the cell. These results suggest p57 controls LIMK-1 and ultimately affects cancer cell motility negatively (18). It is worth noting that the interaction of p57 and LIMK-1 occurs in the cytoplasm, and p57 expression increases in the cytoplasmic fraction and decreases in the nuclear fraction. This contradicts a previous study, which shows that p57 regulates actin dynamics by binding and translocating LIMK-1 from the cytoplasm into the nucleus and cannot affect its activity (12). It has been proved that the binding of p27 and p21 to Rho family, as well as regulation of actin stress fiber occur in the cytoplasm $(46,47)$. These results indicate that the activity and subcellular localization of p57 is critical in the regulation of cancer cell motility (Fig. 2).

Some clinical studies show that decreased expression of p57 is related to increased invasiveness and metastasis in cancers, categorizing it as a tumor metastatic suppressor $(17,48)$. Inducible expression of p57 in glioma cell lines deficient in this CKI reduces their motility and invasiveness (49). In addition, p57 is involved in angiogenesis via regulating VEGF mRNA and protein level, which is an important event in cancer metastasis (50). However, whether p57 promotes or inhibits tumor cell invasiveness and metastasis remains controversial. Some studies indicate that p57 promotes the invasion and metastasis of cancers. Knockdown of p57 inhibits migration in some types of cells and overexpression of p57 induces the depolymerization of actin fibers. p27 and p21 in the cytoplasm, the sibling of p57, decrease actin stress fibers, which result in increased migration, invasion and metastasis in HCC and melanoma $(51,52)$. Furthermore, LIMK-1, the p57 effector, has been shown to either promote or inhibit cell mobility depending on different cellular context $(53,54)$. A study has associated elevated LIMK-1 activity with invasive growth of cancers (55). This signal can represent a cytoplasmic retention of $\mathrm{p} 57$, and consequently a functional inactivation of the tumor suppressor. These studies indicate that p57 may play dual roles in invisiveness and metastasis of cancer depending on different cellular localization and regulators. More studies are needed for complete clarification.

Differentiation and carcinogenesis. p57 plays a critical role in many differentiation processes in all kinds of cells by performing both redundant and specific functions. Different signal transduction pathways regulate p57 expression in different tissues. For example, Notch/Hes signaling control the levels of p57 expression in the differentiation and development of pancreas, lens, pituitary and intestine (56-59). p57 is induced by the myogenic factor MyoD in a p73-dependent manner to participate in myogenesis (60). BMP controls p57 expression to induce cell growth arrest or terminal differentiation in normal primary human epidermal keratinocytes and chondrocytes $(61,62)$. The altered expression of p57 produces undifferentiated and over-proliferative cells that give rise to cancer. It has been shown that carcinogenesis of above-mentioned tissues correlates with the participation of p57 in the abnormal differentiation. In rhabdomyosarcoma development, myoblasts are unable to complete myogenic differentiation because 
PAX3-FOXO1 inhibits p57 transcription via EGR1 (63). In neural tumors, p57 is a direct target of some transcription factors including CTIP2 and bHLH to influence cell fate specification and differentiation $(64,65)$.

p57 is the only CKI required and is the most important during embryogenesis, thereby making the window for mutations in carcinogenesis. Generation of $p 57^{-/-}$mice has revealed a phenotype that closely mimics BWS in humans, which is a familial cancer-prone syndrome and a 1000-fold increase in the risk of childhood tumors (32). Moreover, loss of p57 contributes to the occurence and high risk of soft tissue sarcomas and Wilms' tumors (66). Jin and colleagues found the $p 57^{-/}$mice could develop prostatic intraepithelial neoplasia, a precursor of prostate cancer (67). Moreover, p57 can regulate the cell cycle exit of progenitor cells to control their proliferation and differentiation in the pancreas, crypt of the small intestine, the nervous system, and the hematopoietic system $(56,59,68)$. The dysregulation of stem cells by p57 could constitute an important pathway by which it promotes tumorigenesis in leukemia (68). The uncoupling of the cell cycle exit and differentiation is consistent with cancer stem cell models, which propose that a small number of stem cells underlie the growth of differentiated tumors to produce reoccurence and resistance to treatment.

\section{Carcinogenic mechanism of p57}

The inactivation of p57 occurs in carcinomas of the prostate, bladder, gastrointestinal tract, liver, pancreas, breast, head and neck and others $(19,67,69-73)$. In the past, it was thought that genetic mutation was the principle way of gene inactivation. However, mutational inactivation of $p 57$ is infrequent in malignancies. $p 57$ has been mainly reported to be inactivated via transcriptional and translational modifications in cancers. The abnormal expression of p57 influence malignant biological behavior of cancer cells through following multiple mechanisms.

Loss of imprinting and loss of heterozygosity. p57 is an imprinting gene and lies in the imprinted domain of $11 \mathrm{p} 15.5$. As a growth regulator, monoallelic expression of $p 57$ increases the risk of tumorigenesis and abnormalities (74). Loss of imprinting (LOI) of p57 is frequently observed in a number of human cancers including breast, bladder, lung, ovarian, and testicular carcinomas, as well as several types of childhood tumors, including Wilms' tumor, adrenocortical carcinoma, rhabdomyosarcoma, and hepatocellular carcinoma (16,75-78). It is interesting to note that the embryonal subtype of rhabdomyosarcoma is characterized by loss of the maternal p57 (79). These results suggest that LOI of p57 contributes to the pathogenesis of tumors. DNA methylation and histone deacetylation play an important role in the control of imprinting. p57 is the focal point of the selective pressure for the imprinting of $11 \mathrm{p} 15.5$. There is a 450 - to $500-\mathrm{kb}$ domain extending from $p 57$ to $H 19$ that contains multiple imprinted genes. The establishment of imprinting may be regulated throughout the entire domain. Thus, LOI might simultaneously affect several genes including $I G F 2$ and $H 19$ at this locus that jointly contributes to the tumor and/or growth suppressing functions of p57 $(75,80)$. LOI of p57 is associated with LOH.
$11 \mathrm{p} 11.5$ is a frequent site for $\mathrm{LOH}$ in human cancers, and p57 itself undergoes LOH in 19\% cancers. $\mathrm{LOH}$ of p57 was found in Wilms' tumor, hepatoblastoma, as well as oral, lung, bladder and breast cancer (16). Activation of the paternal allele may be a compensatory response to the loss of the maternal allele, the result of a feedback mechanism to prevent unlimited growth (31).

DNA methylation and histone modification. The main epigenetic modification in humans is DNA methylation and aberrant promoter methylation, which can result in the silencing of $p 57$. The pattern of p57 methylation in tumor cell can be divided into two groups: one with extensive methylation of the entire $\mathrm{CpG}$ island and one methylated only at the region around the transcription start site. p57 methylation participate occurrence, progression and prognosis in many cancers including lymphoma, leukemia, lung, esophageal, gastric, hepatocellular, pancreatic cancers, as well as BWS (81). Tumor suppressor properties of p57 are dependent on its DNA methylation status. Overexpression of p57 in leukemic cell lines with methylated p57 promoter resulted in cell growth arrest and the induction of apoptosis. In contrast, overexpression of p57 in partially methylated cells resulted in a moderate inhibition of cell growth and had no impact on apoptosis (70). In addition, the methylation status of the $p 57$ promoter may represent a biological marker for predicting prognosis in patients. In the low-risk group of diffuse large B-cell lymphoma patients, patients with p57 methylation showed longer overall survival than patients without p57 methylation. Interestingly, all patients with p57 methylation were alive during follow-up (82). Aberrant methylation of p57 is also related with biological aggressive phenotype. The methylation of p57 may contribute to the malignant progression of gastric mucosa-associated lymphoid tissue lymphomas and transformation from the indolent chronic phase to the aggressive blast crisis in chronic myelogenous leukemia (83).

p57 can be repressed through histone modifications in both methylation dependent and independent manner to participate in tumorigenesis. The histone methyltransferases EZH2 can suppress p57 through histone H3 lysine 27 trimethylation (H3K27me3), and p57 can be strongly activated by histone deacetylase inhibitor (HDACi) in breast cancer. Moreover, co-expression of EZH2 and p57 levels provides a stronger predictive power of breast cancer prognosis (84). The increased acetylation of histone $\mathrm{H} 3$ and $\mathrm{H} 4$ at the $p 57$ promoter can induce expression and prevent rhabdoid tumor growth. The HDACi, Romidepsin, are potential therapeutic reagents in the treatment of rhabdoid tumor via specifically restored p57 expression (85). In gastric tumors, treatment using demethylating agents, in cases where the promoter is hypermethylated, or HADCi, in cases where promoter histones are deacetylated, reactivates p57 expression (86). These studies suggest the use of methyltransferase and HDACi to attenuate epigenetic silencing representing a possible therapeutic approach to the treatment of certain tumors.

MicroRNAs. MicroRNAs (miRNAs) can regulate various pathways that can contribute to the development of a tumor 
by targeting oncogenes and tumor suppressor genes (87). Studies show that miRNAs directly target the $3^{\prime}$ untranslated regions of p57 mRNAs to reduce reporter gene expression, as well as diminish p57 protein levels involving cells from quiescence to proliferation. Ectopic regulation of miRNAs on p57 expression results in activation of CDK2 and facilitation of $\mathrm{G} 1 / \mathrm{S}$ phase transition in cancer cells (88). In addition, the silencing of p57 by miRNAs is not attributable to Skp2mediated proteolysis. Until now, miR-25, miR-92b, miR-222 and miR-221 have been shown to regulate p57 both individually and combinatorially in cancer cell lines including cervical, breast and gastric cancer cell lines, as well as leukemia and glioblastoma cell lines $(89,90)$. miR-25, miR-92b and miR-106b control the $\mathrm{p} 57$ level and promote renewal of stem cells $(88,91)$. Some researches indicate that miRNAs can stimulate growth of tumor cells in cancer cell lines and tumor growth in vivo in a mouse xenograft model via p57 (90). In clinical specimens, a significant inverse correlation between miRNAs and p57 was found in gastric cancer tissues and HCC tissues to confirm p57 participation in carcinogenesis via miRNAs regualtion $(90,92)$.

Regulation of signaling pathways. Multiple signaling pathways control p57, a downstream regulator. Any alterations in signaling can cause abnormal function of p57 resulting in tumorigenesis. p57 can be a direct target of transcriptional repression by Notch/Hes1, MyoD, p73, BMP2, and BMP6, IGF2, among others, which participate in the development of pancreatic, colorectal and esophageal cancers, as well as rhabdomyosarcoma, leukemia, melanoma and others $(60,93-96)$. The alteration of transforming growth factor- $\beta$ (TGF- $\beta$ ) signaling pathway is an important and common property of malignant cells, which induces cell cycle arrest in a p57-dependent manner. Upregulation of p57 occurs before the TGF- 3 -induced $\mathrm{G} 1$ cell cycle arrest, which requires transcription and is mediated via a highly conserved region of the proximal p57 promoter. p57 reactivation was observed after stimulation with TGF- $\beta$ in 557 promoter unmethylated cells but not in methylated cells. Reduction of basal p57 expression by this approach also allows hematopoietic cells to proliferate more readily in the absence of TGF- $\beta$ (97). Silencing of p57 can abrogate the TGF- $\beta$-induced inhibition of proliferation in primary human limbal epithelial cells (98). Now it is known that p57 participates in the development of lung cancer, leukemia, myeloma and leiomyoma via TGF- $\beta$ signaling (99-101).

Phosphorylation and ubiquitylation. Notably, some data demonstrate the existence of an inverse correlation of tumor cell proliferation with $\mathrm{p} 57$ protein levels, but not with mRNA levels. This indicates a role of posttranslational modifications in the control of p57. Phosphorylation is an important way to mediate the structure and many biological functions of p57, which has many phosphorylation sites. When the amino acids of p57 are phosphorylated, its affinity for cyclin-CDK complexes and other proteins is altered. Moreover, phosphorylation can change stability of protein and subcellular localization by altering signal pathways (6).

The cellular level of p57 can be controlled by the ubiquitinproteasome pathway in vitro and in vivo involving many ubiquitin ligases. The elimination of p57 is impaired in Skp2-/ cells, resulting in abnormal accumulation of the protein. Overexpression of WT Skp2 promotes degradation of p57, whereas expression of a dominant negative mutant of Skp2 prolonges the half-life of p57. However, p57 degradation also occurs at the G0-G1 transition even in Skp2 ${ }^{-/-}$MEFs indicating that there are other pathways regulating the expression of p57 (10). The F-box protein, FBL12 forms an $\mathrm{SCF}^{\mathrm{FBL} 12}$ complex and contributes to the degradation of $\mathrm{p} 57$ by TGF- $\beta$ stimulation in a phosphorylation-dependent manner. The phosphorylation of p57 at Thr 310 is important for the interaction with FBL12. In addition, the phosphorylation of p57 at Thr-310 is required for SCFSkp2 (Skp1/Cul1/F-box-type E3 ubiquitin ligase complex)mediated ubiquitylation, and the mediation in vitro is in a manner dependent on the presence of the cyclin E-CDK2 complex (102). Mounting evidence underlines the role of ubiquitin ligase in proteasomal degradation of p57 in different tumor types (103). During hepatocarcinogenesis, an increase in Cks1-Skp2 ligase and ubiquitylation of p57 contribute to the susceptibility of developing HCC and are associated with HCC prognosis $(104,105)$. In non-small cell lung cancer, the most important mechanism for regulation of p57 expression is degradation by $\mathrm{Skp} 2$, which is demonstrated both in vivo and in vitro (15).

\section{Perspectives: promoter or inhibitor of cancer?}

The chromosomal location of human p57, at $11 \mathrm{p} 15.5$, marks it as a candidate tumor suppressor gene. There is ample evidence indicating that p57 affects carcinogenesis and biological behavior of tumor cells, the efficacy of anti-cancer agents, and the prognosis of patients. p57 can suppress oncogenemediated transformation of primary cells, which demonstrate that altered p57 expression serve as a 'second hit' during tumorigenesis (13). However, recent studies show that CKI proteins have interesting alternative functions from suppressor to oncogene. In subsets of many human tumor types, the function of the Cip/Kip family is altered by their relocalization to the cytoplasm (23). The upregulation of p21 and p27 in the cytoplasm of many cancer cells indicates that loss of nuclear CKIs is important for cancer cell proliferation. Moreover, increases in cytoplasmic p21 and p27 may be an oncogenic factor, which is involved in high tumor grade, tumor invasion and metastasis (106-108). Although there is no direct evidence to prove that p57 is an oncogene, some researchers have found that p57 expression is high in carcinoma of the colon, pancreas and liver (109-111). In childhood tumors, increased p57 mRNA was found, suggesting an oncogenic role for p57, but protein expression was not examined. Yan et al found $\sim 10 \%$ of p57-null animals survived to adulthood, and no spontaneous tumors were observed at the age of 5 months (32). $p 57$ as a peroxisome proliferator-activated receptor- $\beta$ (PPARß) target gene provides a possible mechanistic explanation for tumor endothelial hyperplasia and deregulation of tumor angiogenesis. The expression of p57 in tumor cells is required for blood vessel formation and tumor growth in $P P A R \beta^{-1-}$ mice. When expressed in the tumor cells, p57 inhibits tumorigenesis by a direct inhibitory effect of tumor cell proliferation, while its expression in tumor 
endothelial cells is required for blood vessel formation and thus tumor growth (112). These results suggest that the loss or subversion of the regulatory mechanisms governing p57 expression may lead to the specific loss of the tumor suppressive function of $\mathrm{p} 57$ while maintaining the oncogenic ones.

Since p57 is the least studied CKI, and many roles of p57 remain controversial, more studies are required to understand the functions of p57 in tumors. It is a matter of perspective in research whether p57 may play a dual role during tumorigenesis. An interesting direction is whether the NLS of p57 affects the subcellular localization resulting in abnormal cell proliferation and motility to act as an oncogene similarly to the $p 21$ and $p 27$. Much work needs to be done.

\section{References}

1. Park MT and Lee SJ: Cell cycle and cancer. J Biochem Mol Biol 36: 60-65, 2003.

2. Matsuoka S, Edwards MC, Bai C, Parker S, Zhang P, Baldini A, Harper JW and Elledge SJ: p5 $7^{\mathrm{KIP} 2}$, a structurally distinct member of the p21 ${ }^{\mathrm{CIP} 1} \mathrm{Cdk}$ inhibitor family, is a candidate tumor suppressor gene. Genes Dev 9: 650-662, 1995.

3. Lee MH, Reynisdottir I and Massague J: Cloning of $\mathrm{p} 57^{\mathrm{KIP} 2}$, a cyclin-dependent kinase inhibitor with unique domain structure and tissue distribution. Genes Dev 9: 639-649, 1995.

4. Awad MM, Sanders JA and Gruppuso PA: A potential role for p15(Ink4b) and p57(Kip2) in liver development. FEBS Lett 483: 160-164, 2000.

5. Nagahama H, Hatakeyama S, Nakayama K, Nagata M and Tomita K: Spatial and temporal expression patterns of the cyclin-dependent kinase (CDK) inhibitors p27 $7^{\mathrm{Kip} 1}$ and p57 ${ }^{\mathrm{Kip} 2}$ during mouse development. Anat Embryol 203: 77-87, 2001.

6. Besson A, Dowdy SF and Roberts JM: CDK inhibitors: cell cycle regulators and beyond. Dev Cell 14: 159-169, 2008.

7. Enklaar T, Zabel BU and Prawitt D: Beckwith-Wiedemann syndrome: multiple molecular mechanisms. Expert Rev Mol Med 8: 1-19, 2006.

8. Hashimoto Y, Kohri K, Kaneko Y, Morisaki H, Kato T, Ikeda K and Nakanishi M: Critical role for the 310 helix region of p57(Kip2) in cyclin-dependent kinase 2 inhibition and growth suppression. J Biol Chem 273: 16544-16550, 1998.

9. Adkins JN and Lumb KJ: Intrinsic structural disorder and sequence features of the cell cycle inhibitor $\mathrm{p} 57^{\mathrm{Kip} 2}$. Proteins 46 : 1-7, 2002.

10. Kamura T, Hara T, Kotoshiba S, Yada M, Ishida N, Imaki H, Hatakeyama S, Nakayama K and Nakayama KI: Degradation of p57 Kip2 mediated by SCFSkp2-dependent ubiquitylation. Proc Natl Acad Sci USA 100: 10231-10236, 2003.

11. Li Y, Millikan RC, Newman B, Conway K, Tse CK and Liu ET: P57 (KIP2) polymorphisms and breast cancer risk. Hum Genet 104: 83-88, 1999.

12. Yokoo T, Toyoshima H, Miura M, Wang Y, Iida KT, Suzuki H, Sone H, Shimano H, Gotoda T, Nishimori S, Tanaka K and Yamada N: p57 $7^{\mathrm{Kip} 2}$ regulates actin dynamics by binding and translocating LIM-kinase 1 to the nucleus. J Biol Chem 278: 52919-52923, 2003.

13. Watanabe H, Pan ZQ, Schreiber-Agus N, De Pinho RA, Hurwitz J and Xiong Y: Suppression of cell transformation by the cyclindependent kinase inhibitor $\mathrm{p} 57^{\mathrm{KIP} 2}$ requires binding to proliferating cell nuclear antigen. Proc Natl Acad Sci USA 95: 1392-1397, 1998.

14. Chang TS, Kim MJ, Ryoo K, Park J, Eom SJ, Shim J, Nakayama KI, Nakayama K, Tomita M, Takahashi K, Lee MJ and Choi EJ: p57 $7^{\mathrm{KIP} 2}$ modulates stress-activated signaling by inhibiting c-Jun NH2-terminal kinase/stress-activated protein kinase. J Biol Chem 278: 48092-48098, 2003.

15. Pateras IS, Apostolopoulou K, Koutsami M, Evangelou K, Tsantoulis P, Liloglou T, Nikolaidis G, Sigala F, Kittas C, Field JK, Kotsinas A and Gorgoulis VG: Downregulation of the KIP family members p27(KIP1) and p57(KIP2) by SKP2 and the role of methylation in p57(KIP2) inactivation in nonsmall cell lung cancer. Int J Cancer 119: 2546-2556, 2006.
16. Pateras IS, Apostolopoulou K, Niforou K, Kotsinas A and Gorgoulis VG: p57 ${ }^{\mathrm{KIP} 2}$ : 'Kip'ing the cell under control. Mol Cancer Res 7: 1902-1919, 2009.

17. Nan KJ, Guo H, Ruan ZP, Jing Z and Liu SX: Expression of p57(kip2) and its relationship with clinicopathology, PCNA and p53 in primary hepatocellular carcinoma. World J Gastroenterol 11: 1237-1240, 2005.

18. Vlachos P and Joseph B: The Cdk inhibitor p57(Kip2) controls LIM-kinase 1 activity and regulates actin cytoskeleton dynamics. Oncogene 28: 4175-4188, 2009.

19. Bozdogan O, Atasoy P, Batislam E, Basar MM and Basar H: Significance of p57(Kip2) down-regulation in oncogenesis of bladder carcinoma: an immunohistochemical study. Tumori 94: 556-562, 2008.

20. Barbe L, Lundberg E, Oksvold P, Stenius A, Lewin E, Bjorling E, Asplund A, Ponten F, Brismar H, Uhlen M and AnderssonSvahn H: Toward a confocal subcellular atlas of the human proteome. Mol Cell Proteomics 7: 499-508, 2008.

21. Bhuiyan ZA, Yatsuki H, Sasaguri T, Joh K, Soejima H, Zhu X, Hatada I, Morisaki H, Morisaki T and Mukai T: Functional analysis of the p57KIP2 gene mutation in Beckwith-Wiedemann syndrome. Hum Genet 104: 205-210, 1999.

22. Matsumoto M, Furihata M, Ohtsuki Y, Sasaguri S and Ogoshi S: Immunohistochemical characterization of $\mathrm{p}^{5} 7^{\mathrm{KIP} 2}$ expression in human esophageal squamous cell carcinoma. Anticancer Res 20: 1947-1952, 2000.

23. Besson A, Assoian RK and Roberts JM: Regulation of the cytoskeleton: an oncogenic function for CDK inhibitors? Nat Rev Cancer 4: 948-955, 2004.

24. Liang J, Zubovitz J, Petrocelli T, Kotchetkov R, Connor MK, Han K, Lee JH, Ciarallo S, Catzavelos C, Beniston R, Franssen E and Slingerland JM: PKB/Akt phosphorylates p27, impairs nuclear import of p27 and opposes p27-mediated G1 arrest. Nat Med 8: 1153-1160, 2002.

25. Li G, Domenico J, Lucas JJ and Gelfand EW: Identification of multiple cell cycle regulatory functions of p57 Kip2 in human $\mathrm{T}$ lymphocytes. J Immunol 173: 2383-2391, 2004.

26. Ullah Z, Lee CY and Depamphilis ML: Cip/Kip cyclin-dependent protein kinase inhibitors and the road to polyploidy. Cell Div 4: $10,2009$.

27. Ullah Z, Kohn MJ, Yagi R, Vassilev LT and De Pamphilis ML: Differentiation of trophoblast stem cells into giant cells is triggered by $\mathrm{p} 57 / \mathrm{Kip} 2$ inhibition of CDK1 activity. Genes Dev 22: 3024-3036, 2008.

28. Gonzalez MA, Tachibana KE, Adams DJ, van der Weyden L, Hemberger M, Coleman N, Bradley A and Laskey RA: Geminin is essential to prevent endoreduplication and to form pluripotent cells during mammalian development. Genes Dev 20: 1880-1884, 2006.

29. Masterson JC and O'Dea S: 5-Bromo-2-deoxyuridine activates DNA damage signalling responses and induces a senescencelike phenotype in p16-null lung cancer cells. Anticancer Drugs 18: 1053-1068, 2007.

30. Yue $\mathrm{H}$ and Jiang HY: Expression of cell cycle regulator p57kip2, cyclin $\mathrm{E}$ protein and proliferating cell nuclear antigen in human pancreatic cancer: an immunohistochemical study. World J Gastroenterol 11: 5057-5060, 2005.

31. Nijjar T, Wigington D, Garbe JC, Waha A, Stampfer MR and Yaswen P: p57 $7^{\mathrm{KIP} 2}$ expression and loss of heterozygosity during immortal conversion of cultured human mammary epithelial cells. Cancer Res 59: 5112-5118, 1999.

32. Yan Y, Frisen J, Lee MH, Massague J and Barbacid M: Ablation of the CDK inhibitor $\mathrm{p} 57^{\mathrm{Kip} 2}$ results in increased apoptosis and delayed differentiation during mouse development. Genes Dev 11: 973-983, 1997.

33. Susaki E, Nakayama K, Yamasaki L and Nakayama KI: Common and specific roles of the related CDK inhibitors p27 and p57 revealed by a knock-in mouse model. Proc Natl Acad Sci USA 106: 5192-5197, 2009.

34. Ma Y and Cress WD: Transcriptional upregulation of p57 (Kip2) by the cyclin-dependent kinase inhibitor BMS-387032 is E2F dependent and serves as a negative feedback loop limiting cytotoxicity. Oncogene 26: 3532-3540, 2007.

35. Yamamoto T, Digumarthi H, Aranbayeva Z, Wataha J, Lewis J, Messer R, Qin H, Dickinson D, Osaki T, Schuster GS and Hsu S: EGCG-targeted p57/KIP2 reduces tumorigenicity of oral carcinoma cells: role of c-Jun N-terminal kinase. Toxicol Appl Pharmacol 224: 318-325, 2007.

36. Ky N, Lim CB, Li J, Tam JP, Hamza MS and Zhao Y: KLF4 suppresses HDACi induced caspase activation and the SAPK path-way by targeting p57(Kip2). Apoptosis 14: 1095-1107, 2009. 
37. Vlachos P, Nyman U, Hajji N and Joseph B: The cell cycle inhibitor p57(Kip2) promotes cell death via the mitochondrial apoptotic pathway. Cell Death Differ 14: 1497-1507, 2007.

38. Samuelsson MK, Pazirandeh A and Okret S: A pro-apoptotic effect of the CDK inhibitor p57(Kip2) on staurosporine-induced apoptosis in HeLa cells. Biochem Biophys Res Commun 296: 702-709, 2002

39. De La Motte Rouge T, Galluzzi L, Olaussen KA, Zermati Y, Tasdemir E, Robert T, Ripoche H, Lazar V, Dessen P, Harper F, Pierron G, Pinna G, Araujo N, Harel-Belan A, Armand JP, Wong TW, Soria JC and Kroemer G: A novel epidermal growth factor receptor inhibitor promotes apoptosis in non-small cell lung cancer cells resistant to erlotinib. Cancer Res 67: 6253-6262, 2007.

40. Gonzalez S, Perez-Perez MM, Hernando E, Serrano M and Cordon-Cardo C: p73beta-mediated apoptosis requires p57kip2 induction and IEX-1 inhibition. Cancer Res 65: 2186-2192, 2005.

41. Hall A: The cytoskeleton and cancer. Cancer Metastasis Rev 28: 5-14, 2009

42. Itoh Y, Masuyama N, Nakayama K, Nakayama KI and Gotoh Y: The cyclin-dependent kinase inhibitors p57 and p27 regulate neuronal migration in the developing mouse neocortex. J Biol Chem 282: 390-396, 2007.

43. Figliola R, Busanello A, Vaccarello G and Maione R: Regulation of p57(KIP2) during muscle differentiation: role of Egr1, Sp1 and DNA hypomethylation. J Mol Biol 380: 265-277, 2008.

44. Heinen A, Kremer D, Gottle P, Kruse F, Hasse B, Lehmann H, Hartung HP and Kury P: The cyclin-dependent kinase inhibitor $\mathrm{p} 57^{\mathrm{kip} 2}$ is a negative regulator of Schwann cell differentiation and in vitro myelination. Proc Natl Acad Sci USA 105: 8748-8753, 2008.

45. Bernard O: Lim kinases, regulators of actin dynamics. Int $\mathbf{J}$ Biochem Cell Biol 39: 1071-1076, 2007.

46. Besson A, Gurian-West M, Schmidt A, Hall A and Roberts JM: $\mathrm{p} 27^{\mathrm{Kip} 1}$ modulates cell migration through the regulation of RhoA activation. Genes Dev 18: 862-876, 2004.

47. Lee $\mathrm{S}$ and Helfman DM: Cytoplasmic $\mathrm{p} 21^{\mathrm{Cip} 1}$ is involved in Ras-induced inhibition of the ROCK/LIMK/cofilin pathway. J Biol Chem 279: 1885-1891, 2004.

48. Fan GK, Xu F, Yang B and Fujieda S: p57(kip2) expression is related to carcinogenesis and tumor progression in laryngeal tissues. Acta Otolaryngol 126: 301-305, 2006.

49. Sakai K, Peraud A, Mainprize T, Nakayama J, Tsugu A, Hongo K, Kobayashi S and Rutka JT: Inducible expression of p5 $7^{\mathrm{KIP} 2}$ inhibits glioma cell motility and invasion. J Neurooncol 68: 217-223, 2004

50. Matsuura T, Takahashi K, Nakayama K, Kobayashi T, ChoiMiura NH, Tomita M and Kanayama N: Increased expression of vascular endothelial growth factor in placentas of p57(Kip2) null embryos. FEBS Lett 532: 283-288, 2002.

51. Wang XQ, Lui EL, Cai Q, Ching WY, Liu KS, Poon RT and Fan ST: p2 $7^{\text {Kipl }}$ promotes migration of metastatic hepatocellular carcinoma cells. Tumour Biol 29: 217-223, 2008.

52. Denicourt C, Saenz CC, Datnow B, Cui XS and Dowdy SF: Relocalized p27 $7^{\mathrm{Kip} 1}$ tumor suppressor functions as a cytoplasmic metastatic oncogene in melanoma. Cancer Res 67: 9238-9243, 2007

53. Bagheri-Yarmand R, Mazumdar A, Sahin AA and Kumar R: LIM kinase 1 increases tumor metastasis of human breast cancer cells via regulation of the urokinase-type plasminogen activator system. Int J Cancer 118: 2703-2710, 2006.

54. Wang W, Mouneimne G, Sidani M, Wyckoff J, Chen X, Makris A, Goswami S, Bresnick AR and Condeelis JS: The activity status of cofilin is directly related to invasion, intravasation, and metastasis of mammary tumors. J Cell Biol 173: 395-404, 2006

55. Yoshioka K, Foletta V, Bernard O and Itoh K: A role for LIM kinase in cancer invasion. Proc Natl Acad Sci USA 100: 7247-7252, 2003

56. Georgia S, Soliz R, Li M, Zhang P and Bhushan A: p57 and Hes 1 coordinate cell cycle exit with self-renewal of pancreatic progenitors. Dev Biol 298: 22-31, 2006.

57. Saravanamuthu SS, Gao CY and Zelenka PS: Notch signaling is required for lateral induction of Jagged1 during FGF-induced lens fiber differentiation. Dev Biol 332: 166-176, 2009.

58. Monahan P, Rybak S and Raetzman LT: The notch target gene HES1 regulates cell cycle inhibitor expression in the developing pituitary. Endocrinology 150: 4386-4394, 2009.
59. Riccio O, van Gijn ME, Bezdek AC, Pellegrinet L, van Es JH, Zimber-Strobl U, Strobl LJ, Honjo T, Clevers H and Radtke F: Loss of intestinal crypt progenitor cells owing to inactivation of both Notch1 and Notch2 is accompanied by derepression of CDK inhibitors p2 $7^{\text {Kip1 } 1}$ and $557^{\text {Kip2 }}$. EMBO Rep 9: 377-383, 2008.

60. Vaccarello G, Figliola R, Cramerotti S, Novelli F and Maione R: p57 $7^{\mathrm{Kip} 2}$ is induced by MyoD through a p73-dependent pathway. J Mol Biol 356: 578-588, 2006.

61. Gosselet FP, Magnaldo T, Culerrier RM, Sarasin A and Ehrhart JC: BMP2 and BMP6 control p57(Kip2) expression and cell growth arrest/terminal differentiation in normal primary human epidermal keratinocytes. Cell Signal 19: 731-739, 2007.

62. Stewart MC, Kadlcek RM, Robbins PD, MacLeod JN and Ballock RT: Expression and activity of the CDK inhibitor p5 $7^{\text {Kip2 }}$ in chondrocytes undergoing hypertrophic differentiation. J Bone Miner Res 19: 123-132, 2004.

63. Roeb W, Boyer A, Cavenee WK and Arden KC: PAX3-FOXO1 controls expression of the $\mathrm{p} 57^{\mathrm{Kip} 2}$ cell-cycle regulator through degradation of EGR1. Proc Natl Acad Sci USA 104: 18085-18090, 2007.

64. Topark-Ngarm A, Golonzhka O, Peterson VJ, Barrett B Jr, Martinez B, Crofoot K, Filtz TM and Leid M: CTIP2 associates with the NuRD complex on the promoter of p57 $7^{\mathrm{KIP} 2}$, a newly identified CTIP2 target gene. J Biol Chem 281: 32272-32283, 2006.

65. Rothschild G, Zhao X, Iavarone A and Lasorella A: E Proteins and Id2 converge on $\mathrm{p} 57^{\mathrm{Kip} 2}$ to regulate cell cycle in neural cells. Mol Cell Biol 26: 4351-4361, 2006.

66. Orlow I, Iavarone A, Crider-Miller SJ, Bonilla F, Latres E, Lee MH, Gerald WL, Massague J, Weissman BE and CordonCardo C: Cyclin-dependent kinase inhibitor p5 $7^{\mathrm{KIP} 2}$ in soft tissue sarcomas and Wilms' tumors. Cancer Res 56: 1219-1221, 1996.

67. Jin RJ, Lho Y, Wang Y, Ao M, Revelo MP, Hayward SW, Wills ML, Logan SK, Zhang P and Matusik RJ: Downregulation of $\mathrm{p} 57^{\mathrm{Kip} 2}$ induces prostate cancer in the mouse. Cancer Res 68: 3601-3608, 2008.

68. Shin DM, Zuba-Surma EK, Wu W, Ratajczak J, Wysoczyns M, Ratajczak MZ and Kucia M: Novel epigenetic mechanisms that control pluripotency and quiescence of adult bone marrowderived Oct $4(+)$ very small embryonic-like stem cells. Leukemia 23: 2042-2051, 2009

69. Larson PS, Schlechter BL, King CL, Yang Q, Glass CN, Mack C, Pistey R, De Las Morenas A and Rosenberg CL: CDKN1C/p57kip2 is a candidate tumor suppressor gene in human breast cancer. BMC Cancer 8: 68, 2008.

70. Kuang SQ, Ling X, Sanchez-Gonzalez B, Yang H, Andreeff M and Garcia-Manero G: Differential tumor suppressor properties and transforming growth factor-beta responsiveness of $\mathrm{p} 57^{\mathrm{KIP} 2}$ in leukemia cells with aberrant $\mathrm{p} 57^{\mathrm{KIP} 2}$ promoter DNA methylation. Oncogene 26: 1439-1448, 2007.

71. Li JQ, Wu F, Usuki H, Kubo A, Masaki T, Fujita J, Bandoh S, Saoo K, Takeuchi H, Kuriyama S, Ishida T and Imaida K: Loss of $\mathrm{p} 57^{\mathrm{KIP} 2}$ is associated with colorectal carcinogenesis. Int J Oncol 23: 1537-1543, 2003

72. Sato N, Matsubayashi H, Abe T, Fukushima N and Goggins M: Epigenetic down-regulation of CDKN $1 \mathrm{C} / \mathrm{p} 57^{\mathrm{KIP} 2}$ in pancreatic ductal neoplasms identified by gene expression profiling. Clin Cancer Res 11: 4681-4688, 2005

73. Lu L, Qiu J, Liu S and Luo W: Vitamin D3 analogue EB1089 inhibits the proliferation of human laryngeal squamous carcinoma cells via p57. Mol Cancer Ther 7: 1268-1274, 2008.

74. Higashimoto K, Soejima H, Saito T, Okumura K and Mukai T: Imprinting disruption of the CDKN1C/KCNQ1OT1 domain: the molecular mechanisms causing Beckwith-Wiedemann syndrome and cancer. Cytogenet Genome Res 113: 306-312, 2006.

75. Feinberg AP: Imprinting of a genomic domain of $11 \mathrm{p} 15$ and loss of imprinting in cancer: an introduction. Cancer Res 59: S1743-S1746, 1999.

76. Kondo M, Matsuoka S, Uchida K, Osada H, Nagatake M, Takagi K, Harper JW, Takahashi T and Elledge SJ: Selective maternal-allele loss in human lung cancers of the maternally expressed $\mathrm{p} 57^{\mathrm{KIP} 2}$ gene at $11 \mathrm{p} 15.5$. Oncogene 12: 1365-1368, 1996.

77. Jelinic P and Shaw P: Loss of imprinting and cancer. J Pathol 211: 261-268, 2007.

78. Thompson JS, Reese KJ, De Baun MR, Perlman EJ and Feinberg AP: Reduced expression of the cyclin-dependent kinase inhibitor gene $\mathrm{p} 57^{\mathrm{KIP} 2}$ in Wilms' tumor. Cancer Res 56: 5723-5727, 1996 . 
79. Anderson J, Gordon A, McManus A, Shipley J and PritchardJones K: Disruption of imprinted genes at chromosome region 11p15.5 in paediatric rhabdomyosarcoma. Neoplasia 1: 340-348, 1999.

80. Matouk IJ, DeGroot N, Mezan S, Ayesh S, Abu-lail R, Hochberg A and Galun E: The H19 non-coding RNA is essential for human tumor growth. PLoS One 2: e845, 2007.

81. Kikuchi T, Toyota M, Itoh F, Suzuki H, Obata T, Yamamoto H, Kakiuchi H, Kusano M, Issa JP, Tokino T and Imai K: Inactivation of $\mathrm{p} 57^{\mathrm{KIP} 2}$ by regional promoter hypermethylation and histone deacetylation in human tumors. Oncogene 21 : 2741-2749, 2002.

82. Lee SM, Lee EJ, Ko YH, Lee SH, Maeng L and Kim KM: Prognostic significance of $\mathrm{O}^{6}$-methylguanine DNA methyltransferase and p57 methylation in patients with diffuse large Bcell lymphomas. APMIS 117: 87-94, 2009.

83. Hayslip J and Montero A: Tumor suppressor gene methylation in follicular lymphoma: a comprehensive review. Mol Cancer 5: 44, 2006.

84. Yang X, Karuturi RK, Sun F, Aau M, Yu K, Shao R, Miller LD, Tan PB and Yu Q: CDKN1C (p57) is a direct target of EZH2 and suppressed by multiple epigenetic mechanisms in breast cancer cells. PLoS One 4: e5011, 2009.

85. Algar EM, Muscat A, Dagar V, Rickert C, Chow CW, Biegel JA, Ekert PG, Saffery R, Craig J, Johnstone RW and Ashley DM: Imprinted $\mathrm{CDKN} 1 \mathrm{C}$ is a tumor suppressor in rhabdoid tumor and activated by restoration of SMARCB 1 and histone deacetylase inhibitors. PLoS One 4: e4482, 2009.

86. Shin JY, Kim HS, Park J, Park JB and Lee JY: Mechanism for inactivation of the KIP family cyclin-dependent kinase inhibitor genes in gastric cancer cells. Cancer Res 60: 262-265, 2000

87. Lynam-Lennon N, Maher SG and Reynolds JV: The roles of microRNA in cancer and apoptosis. Biol Rev Camb Philos Soc 84: 55-71, 2009

88. Sengupta S, Nie J, Wagner RJ, Yang C, Stewart R and Thomson JA: MicroRNA 92b controls the G1/S checkpoint gene p57 in human embryonic stem cells. Stem Cells 27: 1524-1528, 2009.

89. Medina R, Zaidi SK, Liu CG, Stein JL, van Wijnen AJ, Croce CM and Stein GS: MicroRNAs 221 and 222 bypass quiescence and compromise cell survival. Cancer Res 68: 2773-2780, 2008.

90. Kim YK, Yu J, Han TS, Park SY, Namkoong B, Kim DH, Hur K, Yoo MW, Lee HJ, Yang HK and Kim VN: Functional links between clustered microRNAs: suppression of cell-cycle inhibitors by microRNA clusters in gastric cancer. Nucleic Acids Res 37: 1672-1681, 2009.

91. Chen H, Qian K, Tang ZP, Xing B, Chen H, Liu N, Huang X and Zhang S: Bioinformatics and microarray analysis of microRNA expression profiles of murine embryonic stem cells, neural stem cells induced from ESCs and isolated from E8.5 mouse neural tube. Neurol Res, 2009.

92. Fornari F, Gramantieri L, Ferracin M, Veronese A, Sabbioni S, Calin GA, Grazi GL, Giovannini C, Croce CM, Bolondi L and Negrini M: MiR-221 controls CDKN1C/p57 and CDKN1B/p27 expression in human hepatocellular carcinoma. Oncogene 27 5651-5661, 2008.

93. Yang H, Kadia T, Xiao L, Bueso-Ramos CE, Hoshino K, Thomas DA, O'Brien S, Jabbour E, Pierce S, Rosner GL, Kantarjian HM and Garcia-Manero G: Residual DNA methylation at remission is prognostic in adult Philadelphia chromosomenegative acute lymphocytic leukemia. Blood 113: 1892-1898, 2009.

94. De La O JP and Murtaugh LC: Notch signaling: where pancreatic cancer and differentiation meet? Gastroenterology 136 $1499-1502,2009$

95. Reedijk M, Odorcic S, Zhang H, Chetty R, Tennert C, Dickson BC, Lockwood G, Gallinger S and Egan SE: Activation of Notch signaling in human colon adenocarcinoma. Int J Oncol 33: $1223-1229,2008$.

96. Cam H, Griesmann H, Beitzinger M, Hofmann L, Beinoraviciute-Kellner R, Sauer M, Huttinger-Kirchhof N, Oswald C, Friedl P, Gattenlohner S, Burek C, Rosenwald A and Stiewe T: p53 family members in myogenic differentiation and rhabdomyosarcoma development. Cancer Cell 10: 281-293, 2006.
97. Scandura JM, Boccuni P, Massague J and Nimer SD: Transforming growth factor beta-induced cell cycle arrest of human hematopoietic cells requires p57 $7^{\mathrm{KIP} 2}$ up-regulation. Proc Natl Acad Sci USA 101: 15231-15236, 2004

98. Chen Z, Li DQ, Tong L, Stewart P, Chu C and Pflugfelder SC: Targeted inhibition of p57 and p15 blocks transforming growth factor beta-inhibited proliferation of primary cultured human limbal epithelial cells. Mol Vis 12: 983-994, 2006.

99. Kang Y, Ozbun LL, Angdisen J, Moody TW, Prentice M, Diwan BA and Jakowlew SB: Altered expression of G1/S regulatory genes occurs early and frequently in lung carcinogenesis in transforming growth factor-beta1 heterozygous mice. Carcinogenesis 23: 1217-1227, 2002.

100. Baughn LB, Di Liberto M, Niesvizky R, Cho HJ, Jayabalan D, Lane J, Liu F and Chen-Kiang S: CDK2 phosphorylation of Smad2 disrupts TGF-beta transcriptional regulation in resistant primary bone marrow myeloma cells. J Immunol 182: 1810-1817, 2009.

101. Luo X, Ding L, Xu J and Chegini N: Gene expression profiling of leiomyoma and myometrial smooth muscle cells in response to transforming growth factor-beta. Endocrinology 146: 1097-1118, 2005.

102. Kim M, Nakamoto T, Nishimori S, Tanaka K and Chiba T: A new ubiquitin ligase involved in $\mathrm{p} 57^{\mathrm{KIP} 2}$ proteolysis regulates osteoblast cell differentiation. EMBO Rep 9: 878-884, 2008.

103. Kitagawa K, Kotake Y and Kitagawa M: Ubiquitin-mediated control of oncogene and tumor suppressor gene products. Cancer Sci 100: 1374-1381, 2009.

104. Calvisi DF, Ladu S, Pinna F, Frau M, Tomasi ML, Sini M, Simile MM, Bonelli P, Muroni MR, Seddaiu MA, Lim DS, Feo F and Pascale RM: SKP2 and CKS1 promote degradation of cell cycle regulators and are associated with hepatocellular carcinoma prognosis. Gastroenterology 137: 1816-1826, 2009.

105. Calvisi DF, Pinna F, Ladu S, Muroni MR, Frau M, Demartis I, Tomasi ML, Sini M, Simile MM, Seddaiu MA, Feo F and Pascale RM: The degradation of cell cycle regulators by SKP2/CKS1 ubiquitin ligase is genetically controlled in rodent liver cancer and contributes to determine the susceptibility to the disease. Int J Cancer 126: 1275-1281, 2010.

106. Liu Y, Yeh N, Zhu XH, Leversha M, Cordon-Cardo C, Ghossein R, Singh B, Holland E and Koff A: Somatic cell type specific gene transfer reveals a tumor-promoting function for p21(Waf1/Cip1). EMBO J 26: 4683-4693, 2007.

107. Besson A, Hwang HC, Cicero S, Donovan SL, Gurian-West M, Johnson D, Clurman BE, Dyer MA and Roberts JM: Discovery of an oncogenic activity in p27Kip1 that causes stem cell expansion and a multiple tumor phenotype. Genes Dev 21: 1731-1746, 2007

108. Sicinski P, Zacharek S and Kim C: Duality of p $27^{\text {Kip1 }}$ function in tumorigenesis. Genes Dev 21: 1703-1706, 2007.

109. Zhu MH, Ni CR, Zhu Z, Li FM and Zhang SM: [Determination of expression of eight p53-related genes in hepatocellular carcinoma with tissue microarrays]. Ai Zheng 22: 680-685, 2003.

110. Noura S, Yamamoto H, Sekimoto M, Takemasa I, Miyake Y, Ikenaga M, Matsuura $\mathrm{N}$ and Monden M: Expression of second class of KIP protein $\mathrm{p} 57^{\mathrm{KIP} 2}$ in human colorectal carcinoma. Int J Oncol 19: 39-47, 2001.

111. Ito $\mathrm{Y}$, Takeda T, Wakasa $\mathrm{K}$, Tsujimoto $\mathrm{M}$ and Matsuura $\mathrm{N}$ : Expression of p57/Kip2 protein in pancreatic adenocarcinoma. Pancreas 23: 246-250, 2001.

112. Muller-Brusselbach S, Komhoff M, Rieck M, Meissner W, Kaddatz K, Adamkiewicz J, Keil B, Klose KJ, Moll R, Burdick AD, Peters JM and Muller R: Deregulation of tumor angiogenesis and blockade of tumor growth in PPARbetadeficient mice. EMBO J 26: 3686-3698, 2007. 